\title{
El erotismo y la ciudad en la poesía de Luis García Montero
}

\author{
Diego Alejandro GuiLlÉn BolAnd \\ dalguillen@hotmail.com
}

\begin{abstract}
RESUMEN
En la obra poética de Luis García Montero la ciudad cumple un papel fundamental, pues no solo es un escenario, sino que también interactúa con los personajes. Es decir, la ciudad puede sentir, ser un organismo vivo o ser objeto del deseo. Por otra parte, la ciudad es el universo que contiene todos los espacios de la vida cotidiana en los que se desarrolla la poesía del autor: espacios privados como la casa, las habitaciones, los pasillos; y espacios públicos como las calles, los bares, las aceras. En el presente artículo se estudiará la relevancia de estos espacios donde se producen los encuentros eróticos de las personas que habitan la ciudad.
\end{abstract}

Palabras clave: poesía, ciudad, espacios, erotismo, Luis García Montero.

\section{The Eroticism and the City on the Poetry of Luis García Montero}

\begin{abstract}
The city is fundamental on the poetry of Luis García Montero because it is not only a frame, but it also interacts with the characters. The city can feel and it can be a living organism able to provoke erotic desire. On the other hand, the city is the universe that contains all the spaces of the quotidian life: the private spaces and the public spaces. This article will study those spaces where the eroticism occurs.
\end{abstract}

Keywords: poetry, city, spaces, eroticism, Luis García Montero.

La ciudad desempeña un papel principal en la obra de Luis García Montero; en su narrativa, en concreto en la novela Alguien dice tu nombre (2014), la ciudad de Granada juega un rol protagónico e interactúa con la cotidianeidad de los personajes; en su obra ensayística dedica también especial atención al estudio de la ciudad y sus connotaciones en la literatura, en los ensayos contenidos en Los dueños del vacío (2006); y, finalmente, en su -extensa- obra poética otorga a la ciudad una preponderancia notoria, ya que esta no se limita a ser solo un escenario de acontecimientos, sino que también es capaz de sentir como un organismo vivo, de ser el 
cuerpo de la amada, de ser testigo y cómplice, e incluso ser objeto del deseo. En este último ámbito, el de la poesía, se hará hincapié en este estudio con relación al erotismo, que es la materia que ahora nos atañe. Es decir, se estudiarán los roles y los valores que tiene la ciudad, así como también sus espacios públicos, privados y fronterizos en los que pueden propiciarse los encuentros eróticos.

En su poemario Diario cómplice (1987), García Montero presenta la ciudad como un escenario que es proclive para el amor, en el que las calles son un mero decorado donde se suceden episodios amorosos: «Y no la oscuridad, sino esas horas / que convierten las calles en decorados públicos / para el privado amor [...]» (García Montero 2006a: 121). La calle, espacio público por excelencia, donde converge la heterogénea masa de peatones, compuesta por turistas que están de paso por la ciudad, por vendedores ambulantes, por mendigos, por oficinistas camino del trabajo y por la fauna urbana que surge por las noches, puede no obstante ofrecer la intimidad necesaria para el encuentro amoroso: ya sea por la oscuridad, con su velo protector, ya sea por la luz especial de determinadas horas del día, que convierten la ciudad en bello telón de fondo, la publicidad de la calle es sustituida por una ilusión de privacidad.

No solo el espacio público se amolda al encuentro de los sujetos amorosos, sino también el privado: «Aunque también se hicieron / los muebles a nosotros [...]/ en una habitación parecida a la nuestra, / con libros y con cuerpos parecidos / estuvimos amándonos / bajo el primer bostezo de la ciudad» (García Montero 2006a: 121122). La ciudad y, dentro de ella, la casa, en tanto que principal espacio privado, acoge la relación amorosa, ofreciendo un entorno propicio, íntimo, donde los objetos son los únicos testigos. El hogar es, de hecho, el escenario por excelencia de los encuentros eróticos: "Yo sé, / que el tierno amor escoge sus ciudades / y cada pasión tiene su domicilio, / un modo diferente de andar por los pasillos / o de apagar las luces» (García Montero 2011: 73).

La casa deviene en pilar fundamental del amor y de la vida en pareja, por la intimidad que confiere: en ese sentido, esta tiene la facultad de almacenar recuerdos en su interior. Es decir, las estancias evocan la memoria de amores pasados: «Si alguna vez no hubieses existido / si el calor de tus muslos no me hubiese / buscado como un látigo preciso [...] / es posible / que este volver a casa en soledad [...] / me recordase ahora un poco menos / al joven que apostaba por el mundo [...]» (García Montero 2006a: 190). La casa, como núcleo de la vida urbana, simboliza comúnmente un espacio protector para el individuo, un refugio, como apuntan Bachelard (1975), Gullón (1980) o Mejía Ruiz (2010), entre otros. No obstante, el yo poético puede sentirse apresado en dicho lugar; la configuración de la casa como un espacio carcelario se da precisamente por aquel «volver a casa en soledad» que confina al sujeto a vivir atrapado entre un cúmulo de recuerdos que pueblan los pasillos y las habitaciones.

A pesar de su marcado carácter privado, el amor y la pasión, debido a su fuerza desmedida, pueden proyectarse desde la intimidad de la habitación hacia las calles, que son el principal espacio público de la ciudad. En los siguientes versos puede notarse una progresiva extensión de las características del espacio privado al espacio público: «Nos besamos entonces / y tus ojos, los míos, / empiezan a echar humo / para 
poblar las dudas de las habitaciones, / salir por las ventanas de la casa, / enredar las calles y atravesar los barrios, / haciendo que se anegue la ciudad [...]» (García Montero 2011: 92). Se produce, por tanto, una disolución de las fronteras entre espacios cerrados y espacios abiertos, entre espacios privados y espacios públicos, similar a la comentada a propósito de la intimidad de las calles, pero en sentido contrario.

Por otra parte, no es extraño observar en la literatura el tratamiento de la ciudad como un ente vivo lleno de significaciones y sentimientos. Esta metáfora, la de la ciudad-cuerpo, resultante de atribuir a la ciudad rasgos humanos, como la capacidad de sentir o de excitarse, está también muy presente en la obra de García Montero. En el poema «Y cuatro» recogido en Además (1994), por ejemplo, puede observarse esta humanización de la ciudad: «Abajo de tus pies se en- / ciende la ciudad en dos inmensos muslos, y cada esquina espera / que le llegue el orgasmo» (García Montero 2006a: 583). En el verso citado, el poeta realiza un símil de la urbe con un cuerpo humano - es decir, la humaniza-, con una parte concreta de este, las piernas, que representan mediante una sinécdoque a la mujer, y que esperan ser excitadas quizás por los pasos de los peatones y alcanzar el clímax sexual como resultado del vaivén de las esquinas al ser transitadas. Esos muslos de la ciudad pueden distinguirse también en medio de la oscuridad de la noche por su blancura, solo comparable con la de la luna que cuelga del cielo negro: «De pronto se ilumina / en un sillín con prisas la línea femenina / de un muslo. / Las aceras, sin discreción ninguna, / persiguen ese muslo más blanco que la luna» (García Montero 2011: 120). En estos versos la ciudad desempeña un papel ambivalente, pues es a un tiempo objeto de deseo, encarnando a la mujer, y también sujeto presa de ese deseo, una urbe viva capaz de excitarse, que persigue, a través de sus propios elementos constitutivos (como las aceras), la silueta femenina.

Volviendo a la identificación de la urbe con la mujer deseada, la voz poética a menudo se dirige a la ciudad, a los escenarios por los que transita, como a una mujer que la acompaña: «Soy el aparecido de las som- / bras, el que cruza la calle, el que se pierde hacia un destino / secreto. Y te miro un momento, y me poso en tu hombro, y / acerco mis labios a tu cuello» (García Montero 2011: 151). La relación que existe entre ambos, sujeto y ciudad, alcanza en ocasiones la intensidad de una relación sexual. Internarse en las calles supone un contacto directo, a través de besos y caricias, con el cuerpo de la mujer, con el consecuente aumento de la tensión sexual.

En el proceso de humanización de la ciudad, algunos de sus elementos toman incluso la voz, es decir, se convierten en el propio sujeto lírico. Los edificios, concebidos como cuerpo que siente, padecen el dolor de ser habitados por un ser amado que ignora su condición: «Contadle que ella vive / en mi planta más alta y que la vida / de su casa en mi cuerpo es una herida, / [...] cuando siento en el pecho su calor / o la siento cruzarme en ascensor, / subir de piso en piso, / como quien tiene dentro el paraíso» (García Montero 2006a: 632-633). En este poema, «Égloga de los dos rascacielos», una torre de Manhattan atestigua los encuentros sexuales de su amada con otros hombres, siente dolor y celos al ver cómo esta se entrega al cuerpo de otro amante: «[...] y a la vez el infierno. / Suele llegar con alguien, que la besa / poniendo en cada labio una promesa / de amor, extraño y tierno, por dejarme con daño y sin gobierno» (García Montero 2006a: 632-633). 
En esta reescritura en clave urbana de Garcilaso, los actantes y el escenario tradicionales de la égloga se sustituyen por uno solo: la ciudad. El espacio urbano ha reemplazado a la naturaleza y los pastores son ahora dos edificios que dialogan sobre temas amorosos, en este caso el amor que no les es correspondido y que sufren como testigo: «Despacio se desnuda. / Como el náufrago lucha entre ciclones, / en su respiración, los dos pezones / gritan pidiendo ayuda. / [...] pues la veo entregarse, / ya teñida la piel de un rojo leve, / ya tomados los ojos por la nieve» (García Montero 2006a: 632-633). El edificio dirige sus quejas no solo a su semejante, el otro rascacielos, sino también a un sinfín de elementos del paisaje urbano como carteles, letreros, luces y sirenas, entre otros: «Teléfonos alertas, / sirenas que la luz cruzáis veloces, / letreros luminosos, altavoces, / carteleras expertas / que hacéis negocios y mentís ofertas, / yo que acudo al amigo, / os pido que cumpláis la penitencia» (García Montero 2006a: 632). En estos versos se pone de manifiesto la participación conjunta de la urbe en el lamento del amante desolado -el edificio-, él como emisor y el resto de la ciudad como receptora del mensaje. Esta relación de comunicación y, por ende, la personificación, involucra a toda la urbe y a todos afecta; hasta el material más duro -el acero- es sensible al dolor.

En el poemario Y ahora ya eres dueño del Puente de Brooklyn (1980), la ciudad se convierte en un escenario de búsqueda del encuentro erótico. La urbe, que ya no es ni el objeto amado ni el sujeto que ama, se compone de un conjunto de espacios públicos, como las barras de los bares, las calles o los suburbios, por los que el individuo deambula con la intención de mitigar, a través del contacto sexual, la soledad que impera en los espacios privados, la ausencia de una persona amada: «Por ello buscarás un racimo de rabia en los suburbios e / irás desnudo al desafío de labios que sospechas intocables, / porque tu carne toda será un esqueje leve, que condene otra / angustia peor y más extensa: / aquella / que rebota / al pie de los / peatones» (García Montero 2011: 36).

En estos versos se puede apreciar el carácter sensorial que implica el encuentro íntimo, en el cual los cuerpos de los individuos se tocan, se reconocen, se fusionan. Al respecto, Laura Scarano, en su estudio sobre la obra del poeta granadino Las palabras preguntan por su casa (2004: 37), señala que el tacto se torna imprescindible para el reconocimiento de la piel, citando a Roland Barthes, quien, a su vez, sostiene que el contacto entre los amantes requiere de una respuesta que solo la piel es capaz de dar apropiadamente. Así pues, la voz poética exhorta al amante a recorrer la ciudad buscando un roce que llegue a consumar el encuentro erótico; por el contrario, advierte de que, de no tener el valor de dejar al tacto actuar entre las pieles, se verá forzado a sufrir la execrable angustia de encontrarse en una multitud de soledades de la calle.

Sin embargo, ambas situaciones enunciadas por la voz poética, la del coito furtivo o la de la soledad, conducen a un final angustioso. Aunque la desazón será menor si se llega a la cópula, la comunión de los cuerpos es transitoria y a su fin llega de nuevo el vacío, aun cuando el otro cuerpo permanece al lado del propio, en la misma cama, compartiendo la angustia en silencio. La ciudad, cómplice por un tiempo, al brindar primero espacios públicos para el encuentro y, después, la intimidad del recinto privado para la relación sexual, recupera de nuevo su carácter hos- 
til. Frente a la sensación de vacío, el sujeto se encuentra de nuevo ante la disyuntiva de dejarse conducir hacia el encuentro ocasional y efímero o permanecer en el frío de unas calles ajenas.

En contraposición al ejemplo anterior, el de una ciudad ausente, encontramos en la obra de García Montero ciudades llenas de contenido, de significado, hasta el punto de que, como ya apuntaba Roland Barthes en «Semiología y urbanismo» (2003: 264), el yo poético las recorre como una escritura que hay que leer, interpretando sus signos, los mensajes que contiene. En el poema «Invitación» del libro Diario cómplice (1987), el yo poético camina por la ciudad y siente que todos sus elementos se comunican con él: «Y nada es neutro, / ni siquiera las sombras de las casas antiguas / preguntando / su paisaje perdido en las aceras, / ni siquiera la grúa / que lejana, / hermosa como un cisne, / tiende su largo cuello y lo descansa / sobre el alero gris del horizonte» (García Montero 2011: 70). Existe una comunicación entre el sujeto que busca y la ciudad, que otra vez se constituye en un espacio de búsqueda:

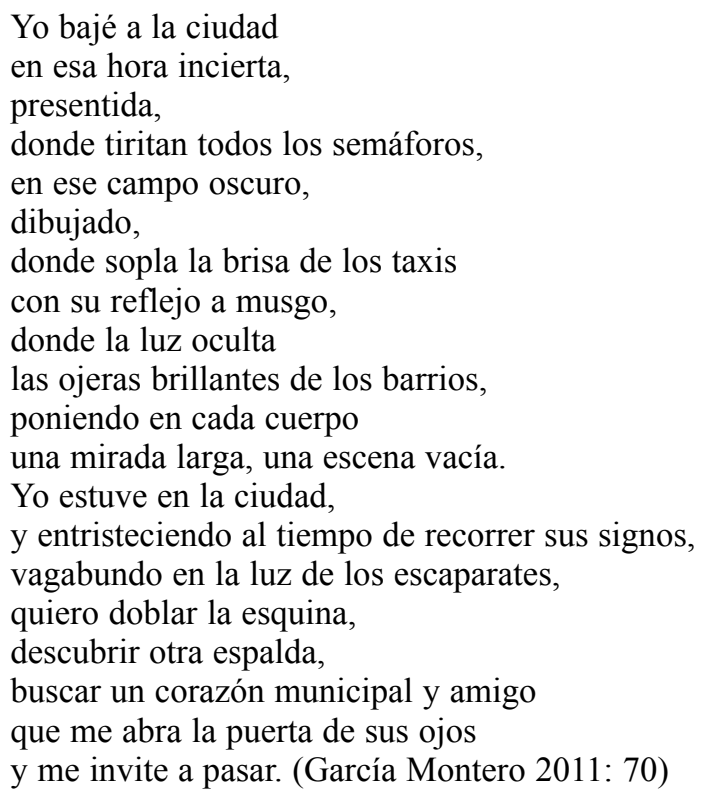

El caminante deambula por la ciudad buscando un amor concreto y la urbe lo guía por sus calles a través de la noche. En su recorrido, el yo poético va percibiendo los distintos elementos del paisaje urbano nocturno: aquellas «ojeras brillantes» lo acompañan al cruzar los barrios y al doblar las esquinas, mientras espera que la ciudad -quizás confundida con el cuerpo de la amante- le deje abierta la puerta de su corazón. Pero estas calles, escenario de la actual búsqueda, contienen vivencias pasadas junto a la amante añorada, que a su paso despiertan los recuerdos: «Pero todo convoca a tu presencia: / mírame regresando. / Los portales abiertos, / los anuncios, / me recuerdan tu piel, / ese reino sin dudas / donde pretendo hablar del hori- 
zonte» (García Montero 2011: 72). Este horizonte termina siendo comparado con una sucia barra de bar en la que nunca se podrá apoyar, haciendo alusión al amor que no podrá recuperar.

Dentro de este entramado urbano, portador de sentido y de recuerdos, detectamos algunos espacios especialmente propicios para el encuentro erótico. Frente a espacios privados, como la casa, que se suponen idóneos a tal fin y que sin embargo no siempre pueden satisfacerlo, algunos espacios públicos usurpan esta función, transgrediendo en buena medida su condición primigenia de «espectáculo público (no privado), una diversión popular, un comercio, entre función teatral y feria» (Castellani 2010: 173). En algunos versos de García Montero, el cine no es sólo el lugar al que asiste gente para ver la proyección de películas, sino que también es un espacio cómplice de amantes que se cobijan en sus butacas y se camuflan en la oscuridad: «No se descarta que al salir del cine / una pareja cuente con nuevos enemigos. / La película es mala, / las sombras buscan cuerpos para encontrar deseos, [...] / pero los labios son materia viva / en las butacas observadas / y los botones pierden su vergüenza» (García Montero 2011: 192). En este poema de Completamente viernes (1998) puede verse una superposición de realidades: una ficticia y otra efectiva. En la ficticia se describen los hechos de la película proyectada y en la efectiva, el lance erótico de los amantes:

Suena un disparo inútil,

la camisa deshecha,

la mano que naufraga entre los muslos.

Se persiguen dos coches por tus hombros

y estalla un edificio,

una lengua de fuego en la ventana,

llamas que desesperan vientre abajo,

el pelo negro por la mano abierta,

negra como la vida en la pantalla,

como el silencio del actor que mira,

del acomodador,

del público encendido. (García Montero 2011: 192)

El cine es cómplice del erotismo: la oscuridad es el elemento que propicia la intimidad entre los sujetos amorosos. Las imágenes de los amantes se superponen a las de la película y se confunden. Por ello, aunque el cine es, en principio, un espacio público, el negro que inunda la sala durante la proyección y que cubre a los amantes y permite el encuentro erótico lo transforma en un espacio fronterizo, justamente por esa dualidad concomitante.

Una transgresión similar, si cabe más llamativa, es la que se produce en espacios provisionales, de tránsito, como los grandes centros comerciales o los polígonos que generalmente se encuentran en el extrarradio, lugares de anonimato, sin identidad, sin carácter relacional ni histórico, esto es, no-lugares, según la definición de Marc Augé (2008), al ser convertidos en escenario erótico. Así pues, «Bajo una lluvia fría de polígono, / con un cielo drogado de tormenta / y nubes de extrarradio» (García 
Montero 2011: 91), se produce un encuentro sexual tan aséptico e impersonal como el mismo espacio donde sucede. Allí, la intimidad no existe, sino que se simula en el momento del encuentro sexual, durante el cual los sujetos amorosos olvidan dónde se encuentran, para regresar, después del coito, a la fría realidad que los rodea: «Porque este amor de llaves prestadas nos envuelve / en una intimidad provisional, / paredes que no hacen compañía / y objetos como búhos en la sombra. / Son / las sábanas más tristes de la tierra. / Mira / cómo vive la gente» (García Montero 2011: 91).

Como se ha podido ver a lo largo de este breve recorrido por la poesía de Luis García Montero, la relación del amor, en general, y del erotismo, en particular, con la ciudad es innegable, por cuanto estos constituyen un impulso primario y necesario del individuo, y la ciudad es su hábitat fundamental. Pero esta ciudad no es homogénea ni plana, sino que presenta diferentes facetas: como escenario, cuenta con espacios en principio anónimos que dan pie al encuentro erótico; con espacios hostiles que muestran su cara más amable mientras se produce el acto sexual, es decir, mientras perdura la ilusión de continuidad que según Bataille (1985) confiere el erotismo; con espacios ligados al individuo o espacios-refugio, que, sin embargo, se convierten en hostiles ante la pérdida o ausencia del ser querido. Pero esta ciudad es mucho más que un decorado; es un actante más del juego amoroso: sujeto que ama, sujeto amado o cómplice que contribuye activamente a la consumación del acto erótico.

Finalmente, se puede observar que los espacios que conforman la ciudad son ambiguos, pues varían sus características o valores en función del desarrollo de los encuentros eróticos. Así pues, un espacio público como la calle puede ser cómplice por un momento al brindar una intimidad ficticia que propicie el erotismo y, por su parte, la intimidad de un espacio privado para la relación sexual recupera de nuevo su carácter hostil ante la soledad que le sigue.

Recorrer la ciudad, a través de los versos de Luis García Montero, supone adentrarse en todas esas historias que en ella han tenido lugar, historias eróticas, pero también de amor y de desengaño, tan complejas, tan cambiantes y tan polisémicas como los espacios que las acogen y atestiguan su existencia.

\section{Bibliografía}

AugÉ, Marc (2008): Los no lugares: Espacios de anonimato. Una antropología de la sobremodernidad. Barcelona: Gedisa.

BACHelard, Gastón (1975): La poética del espacio. México: Fondo de Cultura Económica. BARTHES, Roland (2003): «Semiología y urbanismo», en La aventura semiológica, pp. 257266. Barcelona: Paidós.

BATAILLE, Georges (1985): El erotismo. Barcelona: Tusquets.

CAStellani, Jean-Pierre (2010): «Ficción en el paraíso: el cine», en Eugenia Popeanga (coord.), Ciudad en obras. Metáforas de lo urbano en la literatura y en las artes, pp. 173-186. Berna: Peter Lang.

García Montero, Luis (2006a): Poesía (1980-2005). Barcelona: Tusquets. Incluye: 
- (1982): Tristia.

- (1983): El jardín extranjero.

- (1987): Diario cómplice.

- (1991): Las flores del frío.

- (1994): Habitaciones separadas.

- (1994): Además.

- (1998): Completamente viernes.

- (2003): La intimidad de la serpiente.

- (2006b): Los dueños del vacío. Barcelona: Tusquets.

- (2011): Ropa de calle. Antología poética (1980-2008). Madrid: Cátedra. Incluye:

- (1981): Y ahora ya eres dueño del Puente de Brooklyn.

- (1982): Tristia.

- (1983): El jardín extranjero.

- (1987): Diario cómplice.

- (1991): Las flores del frío.

- (1994): Habitaciones separadas.

- (1998): Completamente viernes.

- (2003): La intimidad de la serpiente.

Gullón, Ricardo (1980): Espacio y novela. Barcelona: Antoni Boch.

Mejía Ruiz, Carmen (2010): «La casa: imagen literaria de un espacio protector», en Eugenia Popeanga (coord.), Ciudad en obras. Metáforas de lo urbano en la literatura y en las artes, pp. 333-347. Berna: Peter Lang.

SCARANO, Laura (2004): Las palabras preguntan por su casa. La poesía de Luis García Montero. Madrid: Visor Libros. 